\title{
Oxidative stability of an extended shelf-life dairy-based beverage system designed to contribute to heart health
}

\author{
R. L. Moore, S. E. Duncan, ${ }^{1}$ A. S. Rasor, W. N. Eigel, and S. F. O'Keefe \\ Department of Food Science and Technology, Virginia Tech, Blacksburg 24061
}

\begin{abstract}
Skim milk, butter-derived aqueous phase, butter oil, and fish oil (3 levels) were used to produce UHT pasteurized n-3 fatty acid-fortified beverages (3.1\% fat, $3.9 \%$ protein, and $11.5 \%$ total solids) with targeted deliveries of 200, 500, and $800 \mathrm{mg}$ of eicosapentaenoic acid and docosahexaenoic acid (combined total) per $250 \mathrm{~mL}(8 \mathrm{fl} \mathrm{oz})$ serving. Microbial quality, emulsion stability, and oxidation of lipids over $35 \mathrm{~d}$ of storage at $4^{\circ} \mathrm{C}$ were evaluated. Conjugated diene hydroperoxides were below $1 \%$ throughout storage and were found at highest concentrations around d 21 of storage for all formulations. Volatile analysis indicated an increase in 1-penten-3-ol in the n-3 fortified dairy-based beverage systems during storage. Triangle tests were conducted to determine if consumers could detect a difference in aroma, compared with commercially processed aseptically packaged milk. The beverage system with targeted delivery of $500 \mathrm{mg}$ of eicosapentaenoic acid + docosahexaenoic acid per $250-\mathrm{mL}$ serving was not different in aroma compared with commercially available UHT processed milk. This formulation delivered $432 \mathrm{mg}$ of heart-healthy n-3 fatty acids per 250-mL serving on d 35 and was microbiologically and physically stable throughout the 35-d refrigerated storage period.
\end{abstract}

Key words: n-3 fatty acid, fish oil, dairy, oxidation

\section{INTRODUCTION}

Increasing medical evidence supports health benefits associated with regular consumption of n-3 FA, such as secondary prevention of coronary heart disease, reduction of inflammation, assistance with infant brain development, and maintenance of brain function (Horrocks and Yeo, 1999; Simopoulos, 1999; Ruxton et al., 2004). Implied health benefits coupled with low consumption of n-3 FA, specifically eicosapentaenoic acid

Received January 20, 2012.

Accepted July 27, 2012.

${ }^{1}$ Corresponding author: duncans@vt.edu
(EPA) and docosahexaenoic acid (DHA), from their natural food sources (Kris-Etherton et al., 2000; Meyer et al., 2003; FDA, 2004), has caused an increased trend in fortification of foods with healthy n-3 FA. According to Product Launch Analytics (Datamonitor, New York, NY), $12.9 \%$ of new foods and beverages in the US market in 2005 to 2010 were labeled as containing high quantities of n-3 FA or DHA (Sprinkle, 2011). United States sales of n-3 FA fortified foods neared $\$ 4$ billion in 2010 and have been predicted to reach $\$ 7$ billion by 2015 (Packaged Facts, 2011). Studies indicate that the current intake of EPA + DHA in the typical western diet is 100 to $200 \mathrm{mg} / \mathrm{d}$ (Kris-Etherton et al., 2000); however, recommendations are significantly higher. For example, the US Department of Agriculture (USDA) Dietary Guidelines suggest consumption of $250 \mathrm{mg}$ of n-3 FA/d (USDA, 2010a), the World Health Organization advises that 1 to $2 \%$ of daily energy intake comes from n-3 PUFA (WHO, 2003), and the American Heart Association recommends 2 servings of fatty fish per week (AHA, 2010).

Dairy products can serve as good food vehicles for delivering n-3 FA and increasing consumption of these healthful lipids. Much work has been done to increase the levels of n-3 FA and the nutritive quality of milk through preharvest technologies such as supplementing dairy cow diets with fish oil (FO), flaxseed, or flaxseed oil (Petit et al., 2002; Lock and Bauman, 2004; Shingfield et al., 2006). Significant increases in n-3 FA levels in the milk of dairy cows have been achieved from addition of FO to feed (Donovan et al., 2000; Shingfield et al., 2006); further, the addition of flaxseed to feed resulted in a favorable n-6-to-n-3 FA ratio (Petit, 2002). A duodenal infusion of linseed oil resulted in an increase of $\alpha$-linolenic acid from 1.0 to $13.9 \%$ of milk FA (Petit et al., 2002). Although preharvest techniques have been shown to be effective in raising n-3 FA levels in milk, the efficiencies of these methods are quite low. Shingfield et al. (2006) reported transfer efficiencies of EPA and DHA from feed to milk of 0.020 and $0.018 \%$, respectively. Additionally, investigators have reported that FO-supplemented diets resulted in decreased concentrations of total fat and protein in the milk (Cant 
et al., 1997; Petit et al., 2002; Shingfield et al., 2006). Postharvest enrichment of milk and dairy products is more efficient and economical.

Recommended criteria for foods that are well suited for fortification with n-3 FA include frequent consumption, as well as processing, storage, and packaging conditions that protect n-3 FA from oxidation (O'Donnell, 2008). Extended shelf-life dairy products, which are recognized for excellent nutritional value, are stored at refrigerated temperature and should be protected from light to protect their inherent nutrient quality. Let et al. $(2005,2006)$ produced an HTST pasteurized FO-enriched milk with $1 \%$ milk fat and $0.5 \%$ (wt/wt) n-3 FA-rich oil. This milk formulation had acceptable sensory characteristics, based on descriptive analysis and consumer acceptability, when the FO was blended with low erucic rapeseed (canola) oil. One 250-mL (8-fl oz) serving of this enriched milk supplied approximately $125 \mathrm{mg}$ of EPA + DHA. At this level of fortification, it would be necessary to drink between two and eleven 8-oz servings of n-3 FA-fortified milk per day, or provide additional supplementation, to achieve the intended health benefits. Enriching milk with enough EPA and DHA per serving to provide heart health benefits would be advantageous as a value-added dairy product.

Challenges associated with incorporating n-3 FArich oil sources into dairy-based systems include sensory issues and oxidative deterioration of these PUFA. Primary sources of n-3 FA are of marine origin (e.g., algae and FO), which may be noticeable in low-flavor systems, such as milk, when used for fortification. Milk fortified with FO is susceptible to aromas indicative of the oil origin as well as from n-3 FA oxidation, which both decreases the nutritional value and produces volatile oxidation end compounds that can negatively affect the aromas or flavors, or both. Extended shelf-life (ESL) dairy-based beverages, which have a refrigerated shelf-life in excess of $30 \mathrm{~d}$, have increased risk of quality and nutritive deterioration from oxidation compared with traditional HTST pasteurized beverages, with 18 to $21 \mathrm{~d}$ of refrigerated shelf-life.

This project evaluated the physical, chemical and sensory stability of an ESL dairy-based fluid beverage system enriched at 3 levels of EPA + DHA per 250-mL (8-fl oz) serving. Specifically, an ESL n-3 FA-fortified dairy-based beverage system with stable physical and microbiological quality for 35 -d shelf-life at $4^{\circ} \mathrm{C}$ was evaluated to

1. monitor oxidative degradation of $\mathrm{n}-3 \mathrm{FA}$ in the dairy-based systems during storage;
2. determine the relationship of FO concentration to volatile chemistry and oxidation of the systems over 35 -d shelf-life at $4^{\circ} \mathrm{C}$;

3. determine if the aromas of the n-3 FA-fortified dairy-based beverages were different than that of a commercially available UHT processed milk, using an untrained panel.

\section{MATERIALS AND METHODS}

\section{Dairy-Based Ingredients and FO for Formulation of Beverage Systems}

Fresh raw milk was heated to $55^{\circ} \mathrm{C}$ and then separated into cream (30 to $35 \%$ milk fat) and skim milk using a pilot plant separator at 6,400 rpm (Elecrem 1G; Bonanza Industries Inc., Calgary, AB, Canada). The skim was vat pasteurized at $63^{\circ} \mathrm{C}$ for $30 \mathrm{~min}$ and then immediately stored at $4^{\circ} \mathrm{C}$ until use. The cream was vat pasteurized at $68^{\circ} \mathrm{C}$ for $30 \mathrm{~min}$ and then immediately cooled via ice bath to $13^{\circ} \mathrm{C}$. Pasteurized cream was tempered overnight in an incubator at $13^{\circ} \mathrm{C}$ and then churned using a mechanical churn (Gem Dandy Standard Electric Churn; Bonanza Industries Inc.) to produce butter and buttermilk. Butter granules were separated from buttermilk by filtering through cheesecloth. Butter granules were rinsed repeatedly with cool water to remove remaining buttermilk. Butter was liquefied by heating to $60^{\circ} \mathrm{C}$ with occasional stirring. Melted butter was transferred into separatory funnels for separation of oil and aqueous phases. The butterderived aqueous phase (BAP) was collected in glass containers, purged with $\mathrm{N}_{2}$ gas, and frozen until use. Butter oil (BO) was transferred into centrifuge bottles and centrifuged at $10,415 \times g$ for $15 \mathrm{~min}$ at $25^{\circ} \mathrm{C}$. Centrifuged BO was decanted from residual BAP into a glass container, purged with $\mathrm{N}_{2}$ gas, and then stored at $-70^{\circ} \mathrm{C}$ until use. Additional BAP was obtained commercially (Grassland Dairy Products Inc., Greenwood, WI) to supplement the BAP source obtained from the laboratory. Upon receipt, BAP was immediately aliquoted into $400-\mathrm{mL}$ volumes and stored at $-18^{\circ} \mathrm{C}$ until use.

Food-grade FO was obtained from a commercial supplier (Omega-3 TG; Ocean Nutrition Canada Ltd., Dartmouth, NS, Canada). Fish oil consisted of anchovy oil, sardine oil, canola oil, natural flavor, tocopherols, sunflower oil, and citric acid. The ratios of the oils and the levels of added antioxidants, all considered proprietary, were not disclosed on the package label. Fish oil was aliquoted into 40-mL amber glass bottles, purged with $\mathrm{N}_{2}$ gas, and stored at $4^{\circ} \mathrm{C}$ until use. 
Table 1. Composition of n-3 FA-fortified dairy-based beverage formulation based upon lipid content (3.25\% targeted total fat) with targeted $\mathrm{n}-3 \mathrm{FA}$ per serving $(250 \mathrm{~mL})$

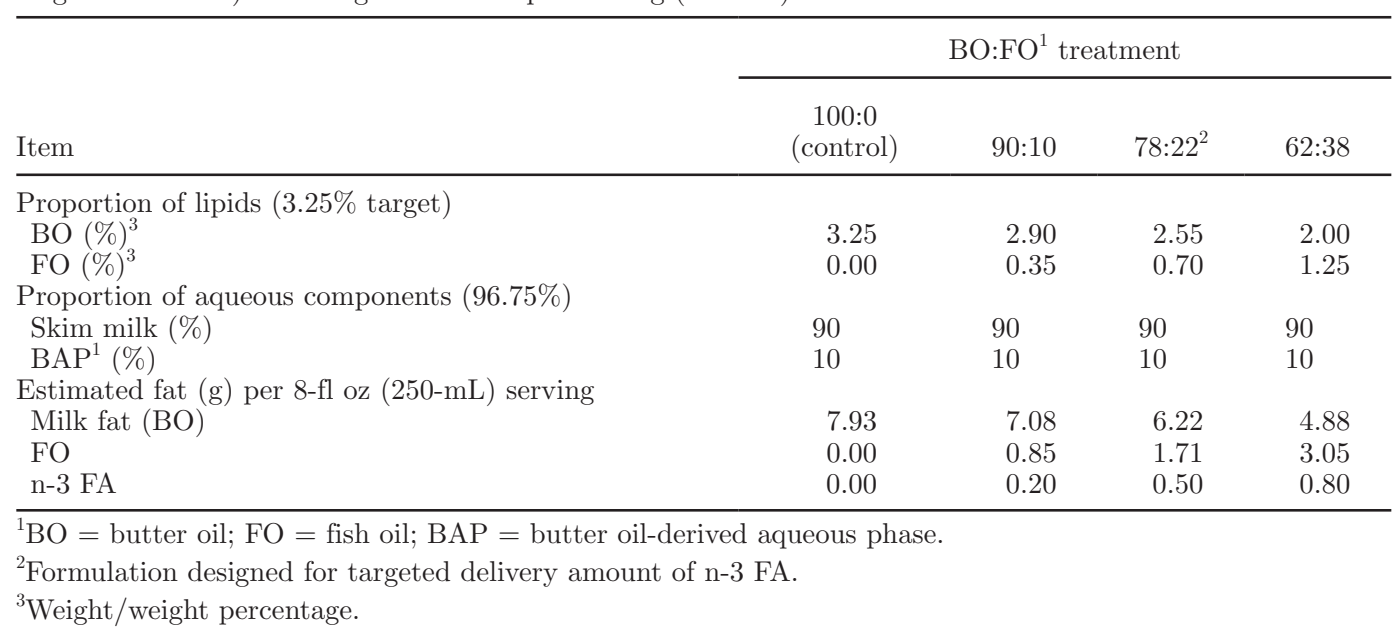

$\boldsymbol{F A}$ Profiles of $\boldsymbol{F O}$ and $\boldsymbol{B O}$. Fatty acid profiles of $\mathrm{FO}$ and $\mathrm{BO}$ were determined before formulation of the dairy-based beverage systems, using gas chromatography, after conversion to FA methyl esters (FAME) following American Oil Chemists' Society (AOCS) methods (AOCS, 1998; method Ce 1b-89). A Shimadzu QP 5050 gas chromatograph-mass spectrometer (Shimadzu Corp., Kyoto, Japan) equipped with an SP-2560 capillary column $(100 \mathrm{~m} \times 0.25 \mathrm{~mm}$; cross-linked and bonded bis-cyanopropyl polysiloxane; Supelco Corp., Sigma-Aldrich Inc., St. Louis, MO) was used for FA analysis. The helium carrier gas flow was $26.9 \mathrm{~cm} / \mathrm{s}$ and column flow was $1.7 \mathrm{~mL} / \mathrm{min}$. A program using a split ratio of $1: 20$, injector temperature of $270^{\circ} \mathrm{C}$, and detector temperature of $230^{\circ} \mathrm{C}$ was used. The initial run temperature was $130^{\circ} \mathrm{C}$ and was increased to $240^{\circ} \mathrm{C}$ at a rate of $2^{\circ} \mathrm{C} / \mathrm{min}$, with a hold time of $10 \mathrm{~min}$. The total run time was $65 \mathrm{~min}$. Fatty acids were identified using a quadrupole mass analyzer. Solvent $(1 \mu \mathrm{L})$ was directly injected into the gas chromatograph-mass spectrometer for analysis. A 37-component FAME mixture (Supelco Inc., Bellefonte, PA) was used as an external reference standard to identify retention times of FAME. Eicosapentaenoic acid and DHA FAME in the FO, as well as other major FAME in the FO and BO, were quantified. Methyl tricosanoate (C23:0) methyl ester $(25 \mathrm{mg} / \mathrm{mL}$; $\mathrm{Nu}$-Chek Prep Inc., Elysian, MN) was used an internal standard and was added $(1 \mathrm{~mL})$ to lipid samples before quantification.

Conjugated Diene Values of $\mathrm{FO}$ and $\mathrm{BO}$. Conjugated diene (CD) values were determined for $\mathrm{BO}$ and FO following AOCS (1998; method Ti 1a-64). Each lipid was dissolved in isooctane to achieve stock solutions of $1 \mathrm{~g} / \mathrm{L}$. Stock solutions were diluted using isooctane to prepare test solutions of approximately 0.4 $\mathrm{g} / \mathrm{L}$. Absorbance at $233 \mathrm{~nm}$ was measured in triplicate for each test solution using a Shimadzu UV-2101PC UV-VIS scanning spectrophotometer (Shimadzu Scientific Instruments Inc., Columbia, MD). Results were reported as percentage conjugated dienoic acid.

\section{Production of n-3 Fortified Dairy-Based Beverage Systems}

Four dairy-based beverages were prepared with different ratios of FO:BO. Formulations targeting 3.25\% total fat content, but differing in FA concentration based on FO content, were prepared using skim milk, BAP, BO, and FO (Table 1).

Dairy-based beverage formulations were homogenized and ultra-pasteurized. Homogenization occurred in 2 stages (13.6 and 3.4 MPa) using a laboratory homogenizer (NS2006H laboratory in-line homogenizer; MicroThermics Inc., Raleigh, NC) and ultra-pasteurized using a tubular laboratory pasteurization system (UHT/ HTST laboratory 25-HV; MicroThermics Inc.) at $148^{\circ} \mathrm{C}$ for $2 \mathrm{~s}$. Immediately after processing, formulations were transferred into sterilized $40-\mathrm{mL}$ glass containers (for physical properties analysis), 100-mL graduated cylinders (for testing of emulsion stability), or 1-L glass containers (for sensory evaluation) and stored in the dark at $4^{\circ} \mathrm{C}$ for up to $35 \mathrm{~d}$.

\section{Evaluation of Physical and Chemical Quality Parameters}

The sampling schedule for all analyses (microbiological, compositional, and chemical quality parameters) is provided in Table 2. Standard plate counts of aerobic, coliform, and yeast and mold organisms were performed 
Table 2. Sampling and analysis schedule for n-3 FA-fortified dairy-based beverage systems stored at $4^{\circ} \mathrm{C}$

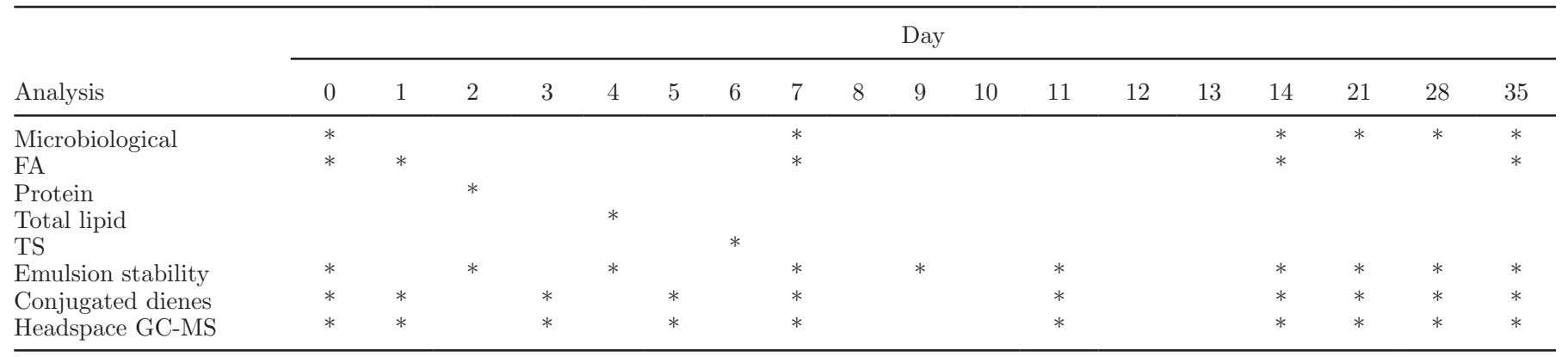

based on standard methods (Laird et al., 2004) to ensure that each dairy-based beverage was properly pasteurized and maintained satisfactory microbial quality. Total fat, by Babcock procedure, and TS content were determined by standard methods (Hooi et al., 2004a,b). Analyses of total fat and TS were performed in duplicate. Protein content was determined spectrophotometrically using a dye-binding assay (RC DC Bio-Rad assay; Bio-Rad Laboratories Inc., Hercules, CA) with BSA (Sigma-Aldrich Inc.) as the standard.

FA Analysis. Lipids were extracted using a modified Folch method (Folch et al., 1957). Fatty acid profiles were determined from extracted lipids using a Shimadzu GC-17A gas chromatograph (Shimadzu Scientific Instruments Inc.) following the procedure described above.

Emulsion Stability. Emulsion stability of dairybased beverages was determined over $35 \mathrm{~d}$ of storage following the procedures of Elling and Duncan (1996). Emulsion stability was tested frequently over the first $14 \mathrm{~d}$ of storage and then on a weekly basis (Table 2). On each test day, each dairy-based beverage formulation was tested in duplicate using the Babcock procedure (Hooi et al., 2004a). The change in fat content in top and bottom layers within each cylinder was calculated.

Determination of Oxidative Stability. Oxidation of lipids in the dairy-based beverages was tracked as a function of time during the 35-d storage period. Lipids were extracted from the dairy-based beverages using the modified Folch method (Folch et al., 1957) previously described. Extracted lipids were transferred into storage containers, purged with $\mathrm{N}_{2}$ gas, and stored at $-80^{\circ} \mathrm{C}$ until analysis. Oxidation was assessed via determination of conjugated dienes and FA analysis, as described above. Conjugated diene analysis (AOCS, 1998; method Ce 1b-89) was used to monitor hydroperoxide development originating from oxidation of FA. Fatty acid analysis (AOCS, 1998; method Ti 1a-64) was used to determine changes in n-3 lipid concentration over time. Analyses were performed on each formulation according to the schedule in Table 2.
Determination of Volatile Chemistry by Solid-Phase Micro-Extraction GC-MS. Volatile oxidation compounds formed during storage of the dairy-based beverages were monitored using a solidphase micro-extraction (SPME) method coupled with GC-MS. On the day of production, 1-g aliquots of each formulation were transferred into $20-\mathrm{mL}$ amber glass headspace vials, sealed with headspace aluminum caps equipped with polytetrafluoroethylene septa, and stored at $4^{\circ} \mathrm{C}$ until analysis.

Volatile oxidation compounds were extracted and concentrated using a conditioned 75- $\mu \mathrm{m}$ Carboxen/ polydimethylsiloxane SPME fiber (Supelco Inc.). A blank was used to ensure that extraneous compounds adsorbed from the atmosphere were desorbed from the fiber before sample analysis. Sample vials were heated to $50^{\circ} \mathrm{C}$ while being agitated at $250 \mathrm{rpm}$. The SPME fiber was exposed $22 \mathrm{~mm}$ into the vial headspace for 15 min during heating and agitation. Volatile oxidation products adsorbed onto the SPME fiber were desorbed and analyzed using an HP 5890A gas chromatograph (Hewlett-Packard Co., Palo Alto, CA) coupled with an HP 5972 series mass selective detector (HewlettPackard Co.). A DB-5 capillary column $(30-\mathrm{m} \times 0.25-$ $\mathrm{mm}$ i.d. $\times 0.25-\mu \mathrm{m}$ film thickness; J\&W Scientific Inc., Folsom, CA) was used for separation of volatiles. The injector temperature was $250^{\circ} \mathrm{C}$, detector temperature was $265^{\circ} \mathrm{C}$, and the program was run in splitless mode with helium carrier gas at a constant flow rate of $1 \mathrm{~mL} /$ min. The initial oven temperature was $35^{\circ} \mathrm{C}$ and was held for $7 \mathrm{~min}$. The temperature then was increased to $120^{\circ} \mathrm{C}$ at a rate of $5^{\circ} \mathrm{C} / \mathrm{min}$ and then to $220^{\circ} \mathrm{C}$ at a rate of $10^{\circ} \mathrm{C} / \mathrm{min}$ and held for $10 \mathrm{~min}$ (Jimenez-Alvarez et al., 2008). The total GC run time was 44 min. Oxidation volatiles were identified by MS internal library searches and comparison of retention times of external standards. Solid-phase micro-extraction GC-MS was performed on each formulation on days indicated in Table 2. External standards of acetaldehyde, propanal, pentanal, 1-penten-3-one, 1-penten-3-ol, hexanal, and 2,4-heptadienal were used to identify and track oxi- 
dation products. Fresh and oxidized (via exposure to direct sunlight) reference samples of $\mathrm{FO}$ and $\mathrm{BO}$, as well as commercially available UHT milk ( $2 \%$ fat), were analyzed for headspace volatiles to help identify compounds that may be present during storage of the dairy-based beverages.

\section{Sensory Evaluation of Dairy-Based Beverage Systems}

This sensory study was approved by the Institutional Review Board of Virginia Tech (Blacksburg). The 78:22 BO:FO dairy-based formulation was evaluated within $1 \mathrm{wk}$ of production to determine if addition of FO influenced the aroma of the dairy-based beverage. Participants $(\mathrm{n}=25)$ were faculty, students, and staff from the Food Science and Technology Department. Although panelists were not trained for this study, some had participated previously in dairy sensory evaluation projects and had some previous training in oxidative aroma detection and evaluation. Triangle tests (Meilgaard et al., 2006) were used to determine if aroma characteristics of the FO-fortified dairy-based beverage system were different from a commercial UHT-pasteurized aseptically packaged 2\% fat milk (Parmalat SpA, Parma, Italy) containing no FO.

Approximately $15 \mathrm{~mL}$ of each dairy product was poured into 1-oz (29.6-mL) plastic soufflé cups and capped. Samples were assigned 3-digit codes and randomized for a balanced order of presentation to sensory panelists. Panelists were presented with 2 sets of 3 samples $\left(4^{\circ} \mathrm{C}\right)$. Panelists smelled each sample in the order presented and were asked to identify the odd sample in each set. Sensory tests were conducted under white fluorescent lighting. Sensory Information Management System software (SIMS 2000; Sensory Computer Systems LLC, Morristown, NJ) was used for sensory test design and data analysis.

\section{Statistical Analysis}

Two replications of the entire study were done. Analytical testing was completed in duplicate within each replication, with the exception of FA analyses. The main factors in the experiment were the ratio of lipids (n-3:milk fat), time, and replication. However, because time was not independent, a 2-way ANOVA with repeated measures was used to assess changes in oxidation and physical stability due to the ratio of lipids. Statistical analyses were completed using JMP (SAS Institute Inc., Cary, NC). An $\alpha$-level of 0.05 was preset for determining significant differences. The Fisher least significant difference test was used for mean separation when significant differences were found. Sensory data from triangle tests were analyzed based upon statistical parameters of $\alpha=0.05, \beta=0.4, \mathrm{P}_{\mathrm{d}}=30 \%$, and equations outlined in Meilgaard et al. (2006) for commingled data.

\section{RESULTS AND DISCUSSION}

\section{Physical and Chemical Quality of Beverage Systems}

Dairy formulations (means \pm SD) were similar in total fat $(3.08 \pm 0.08 \%)$, protein $(3.89 \pm 0.83 \%)$, TS $(11.45 \pm 0.17 \%)$, and total SNF $(8.37 \pm 0.21 \%)$ to the composition of whole milk. Ultra-high temperature processing of the dairy-based beverages and refrigerated storage conditions effectively controlled microbial growth during the 35-d storage period. No significant difference $(P>0.05)$ was observed in change in percentage of fat of the upper and bottom layers of the emulsions during storage, indicating that the beverages were properly homogenized and were physically stable over the 35-d storage period. Differences in emulsion stability were significant between replications $(P<$ $0.05)$. This significance is attributed to natural variability. In a system of this nature, it is challenging to balance the phospholipid component with the protein and lipid load. Minor differences, not measurable by gross analyses, may have influenced the emulsion stability.

\section{FA Profiles of Beverage Systems}

The FO used in this study contained a total of $33.5 \%$ n-3 FA (21.4\% EPA and 12.1\% DHA). Using tricosanoic acid (C23:0) methyl ester as the internal standard, the amount of $\mathrm{n}-3 \mathrm{FA}$ in the $\mathrm{FO}$ was determined to be $335.7 \mathrm{mg} / \mathrm{g}$ of FO. The amounts of EPA and DHA were determined to be 214.4 and $121.3 \mathrm{mg} / \mathrm{g}$ of FO, respectively. The long-chain FA in $\mathrm{BO}$ were myristic, palmitic, stearic, oleic, and linoleic acids, which are characteristic of milk fat. Fatty acids from both FO and $\mathrm{BO}$ were present in the dairy-based beverages, as appropriate for their formulations (Table 1). Table 3 shows the major FA in the extracted lipids from FO, $\mathrm{BO}$, and both the 100:0 and 78:22 (BO:FO) dairy-based beverages during storage. Milk naturally contains very low levels of n-3 FA (approximately $0.25 \%$ of total FA; Donovan et al., 2000), but they were not detected in the $100 \%$ BO (control) formulation in this study.

The FO-fortified dairy-based beverages contained different amounts of n-3 FA among formulations, reflecting levels of fortification. Levels of $n-3 \mathrm{FA}$ in all fortified beverages decreased during storage, suggesting that oxidation of lipids occurred (Table 4). The total n-3 FA decrease over $35 \mathrm{~d}$ of storage [mg of n-3 $\mathrm{FA} / 8 \mathrm{fl} \mathrm{oz}(250 \mathrm{~mL})]$ in all fortified formulations ranged 
Table 3. Concentrations of major FA identified in fish oil (FO) and butter oil (BO) source lipids and UHT-processed n-3 FA-fortified dairybased beverage $(78: 22, \mathrm{BO}: \mathrm{FO})$ during $35 \mathrm{~d}$ of storage at $4^{\circ} \mathrm{C}$

Lipid concentration $[\mathrm{mg} / \mathrm{g}$; mean $(\mathrm{SD})]$

\begin{tabular}{|c|c|c|c|c|c|c|}
\hline \multirow{2}{*}{ FA } & \multirow{2}{*}{\multicolumn{2}{|c|}{ Lipid source }} & \multirow{2}{*}{\multicolumn{2}{|c|}{ 100:0, BO:FO }} & & \\
\hline & & & & & \multicolumn{2}{|c|}{$78: 22, \mathrm{BO}: \mathrm{FO}^{1}$} \\
\hline $4: 0$ & $\mathrm{ND}^{4}$ & $1.1(0.3)$ & 0.9 & $0.5(0.4)$ & 0.5 & $0.5(0.1)$ \\
\hline $6: 0$ & ND & $3.2(1.1)$ & 4.8 & $2.4(0.4)$ & 3.1 & $2.4(0.3)$ \\
\hline 8:0 & ND & $3.4(1.0)$ & 4.9 & $2.8(0.7)$ & 3.0 & $2.9(0.2)$ \\
\hline 10:0 & ND & $10.6(3.1)$ & 13.6 & $8.8(2.5)$ & 9.2 & $9.5(0.9)$ \\
\hline $12: 0$ & $0.9(0.0)$ & $14.9(3.7)$ & 17.8 & $12.2(4.1)$ & 12.5 & $14.0(2.2)$ \\
\hline $16: 0$ & $146.1(11.1)$ & $207.3(5.4)$ & 218.5 & $143.1(61.5)$ & 179.9 & $183.4(25.4)$ \\
\hline $16: 1$ & 78.0 & $10.7(2.1)$ & 12.6 & $7.6(2.9)$ & 23.4 & $22.5(1.2)$ \\
\hline $18: 0$ & $27.4(2.1)$ & $81.3(1.4)$ & 82.0 & $58.7(30.4)$ & 63.9 & $66.9(11.8)$ \\
\hline $18: 1$ n-9 & $90.2(4.0)$ & $230.8(28.3)$ & 219.3 & $146.0(72.6)$ & 168.1 & $171.9(30.7)$ \\
\hline $18: 2$ n-9 & $10.3(0.5)$ & $26.5(0.7)$ & 27.9 & $19.5(10.7)$ & 21.7 & $21.2(2.2)$ \\
\hline $20: 5 n-3$ & $211.6(3.9)$ & ND & ND & ND & 40.3 & $37.6(5.5)$ \\
\hline $22: 6$ n-3 & $113.0(15.2)$ & ND & ND & ND & 20.7 & $19.8( \pm 4.2)$ \\
\hline
\end{tabular}

${ }^{1}$ Formulation designed for targeted delivery amount of n-3 FA.

${ }^{2} \mathrm{n}=2$ replications.

${ }^{3} \mathrm{n}=1$ replication.

${ }^{4} \mathrm{ND}=$ not detected.

from 6.6 to $34.4 \%$, with the 78:22 BO:FO formulation exhibiting the smallest decrease and the 90:10 BO:FO formulation exhibiting the largest. Antioxidants present in the FO (tocopherols, as stated on the product label) may have limited the extent of lipid oxidation in the dairy beverages. Use of tocopherols in the FO for protection of unsaturated FA from oxidation may have delayed oxidation in the dairy beverages; oxidation would have progressed more rapidly once the antioxidants were consumed.

The 78:22 BO:FO formulation provided $431.8 \mathrm{mg}$ of n-3 FA per 8 -fl oz $(250-\mathrm{mL})$ serving on d 35 (86\% of the targeted value of $500 \mathrm{mg}$ of n-3 FA per 8-fl oz serv- ing). Though oxidation occurred, as suggested by the reduction of n-3 lipid levels, the concentrations of n-3 FA present in the target formulation were maintained at a level that would deliver a significant amount of the recommended daily intake of $\mathrm{n}-3 \mathrm{FA}$, thus providing a dietary source that would be easily incorporated into the daily diet. One serving per day of this formulation, over the course of $1 \mathrm{wk}$, would provide $3,019 \mathrm{mg}$ of $\mathrm{n}-3$ FA. This amount is roughly equivalent to the amount of n-3 FA found in 2 servings of fatty fish, such as salmon $[\sim 1,825 \mathrm{mg}$ of EPA + DHA per $3-\mathrm{oz}(88.7-\mathrm{mL})$ serving; USDA, 2010b], and is the American Heart Association recommended weekly intake (AHA, 2010). Let

Table 4. Levels of n-3 fatty acid in n-3 FA-fortified dairy-based beverages [8 oz $(250 \mathrm{~mL}) /$ serving] during 35 d storage at $4^{\circ} \mathrm{C}$

\begin{tabular}{llrrr}
\hline $\begin{array}{l}\text { Formulation } \\
(\text { BO:FO) }\end{array}$ & FA $^{1}$ & $\begin{array}{c}\text { d } 0^{2} \text { mean } \\
(\mathrm{mg} / 8 \mathrm{oz})\end{array}$ & $\begin{array}{c}\mathrm{d} 35^{2} \text { mean } \\
(\mathrm{SD} ; \mathrm{mg} / 8 \mathrm{oz})\end{array}$ & $\begin{array}{c}\text { Decrease } \\
(\%)\end{array}$ \\
\hline $90: 10$ & EPA & 156.6 & $101.5(23.3)$ & 35.1 \\
& DHA & 75.3 & $50.6(11.6)$ & 32.8 \\
$78: 22^{3}$ & Total n-3 & 231.8 & $152.1(34.9)$ & 34.4 \\
& EPA & 312.3 & $288.5(32.9)$ & 7.6 \\
$62: 38$ & DHA & 160.5 & $431.8(54.7)$ & 5.4 \\
& Total n-3 & 462.4 & $458.4(18.3)$ & 6.6 \\
& EPA & 546.2 & $244.8(8.0)$ & 16.1 \\
& DHA & 271.1 & $695.3(18.4)$ & 9.7 \\
& Total n-3 & 799.5 & & 13.0 \\
\hline
\end{tabular}

${ }^{1} \mathrm{EPA}=$ eicosapentaenoic acid; DHA $=$ docosahexaenoic acid

${ }^{2}$ One replication for d 0; 2 replications for d 35.

${ }^{3}$ Formulation designed for targeted delivery amount of n-3 FA. 
et al. (2005) produced an HTST-processed FO-enriched milk product that contained approximately $125 \mathrm{mg}$ of EPA + DHA/8 fl oz. Other currently-marketed n-3 FAfortified milk products provide much smaller amounts of EPA + DHA. For example, Horizon Organic DHA Omega-3 milk (Horizon, Broomfield, CO) provides 32 mg of EPA + DHA per 8-fl oz serving.

\section{Determination of Oxidative Stability of n-3 FA-Fortified Dairy Based-Beverages}

Susceptibility to oxidization of added PUFA was of concern due to loss of EPA and DHA and the production of oxidative products that contribute to negative sensory qualities. Conjugated diene hydroperoxides are primary oxidation products formed upon oxidation of the lipids present in the sample. The initial conjugated diene values (means $\pm \mathrm{SD}$ ) for $\mathrm{FO}$ and $\mathrm{BO}$ source oils were determined to be $0.99 \pm 0.08$ and $0.70 \pm 0.02 \%$, respectively, indicating lack of oxidation. Initial CD values for each formulation were proportional to the amount of FO in the formulation and were typically below $1.0 \%$ for all formulations throughout storage (Figure 1). All formulations exhibited a spike in percentage of conjugated dienoic acid around d 21 of storage, suggesting that the highest level of lipid oxidation occurred around that time.

Linear regression trend lines (Figure 1) indicate that an overall, but not significant $(P>0.05)$, increase in CD formation occurred in FO-containing dairy-based formulations during the $35-\mathrm{d}$ storage period. It is hypothesized that the indirect antioxidants associ- ated with the FO were rapidly overwhelmed by the propagation of the autoxidation reactions within the dairy-based beverage. Therefore, the additional unsaturated FA from the FO were rapidly oxidized after the antioxidants were depleted. The trend lines exhibited steeper slopes for n-3 FA-fortified beverages than for the 100\% BO formulation. The increase in CD values suggests that as storage time increased, oxidation of lipids occurred. Frankel (1998) reported that CD formation parallels the formation of hydroperoxides, which occurs in the early stages of lipid oxidation, as well as subsequent decomposition into secondary oxidation products. Marmesat et al. (2009) reported that in highlinoleic and high-oleic sunflower oils, CD values of 2.6 and $1.7 \%$, respectively, corresponded to peroxide values of $2 \mathrm{mEq}$ of $\mathrm{O}_{2} / \mathrm{kg}$ of oil, which generally indicates a slight degree of oxidation. It may be concluded that CD values less than 1 , as observed in these products, indicate a low degree of oxidation.

\section{Volatile Analyses for Aroma and Oxidative Stability Indices}

Analysis of volatile compounds via SPME/GC-MS was used to monitor the formation of volatile oxidation products that could negatively affect the aroma qualities of the n-3 FA-fortified dairy-based beverages. Polyunsaturated FA present in FO, mainly n-3 FA, form lipid hydroperoxides upon oxidation. Lipid hydroperoxides are odorless and tasteless (Frankel, 1991), but further oxidation of these compounds into secondary oxidation products accounts for the off-aromas and -flavors found

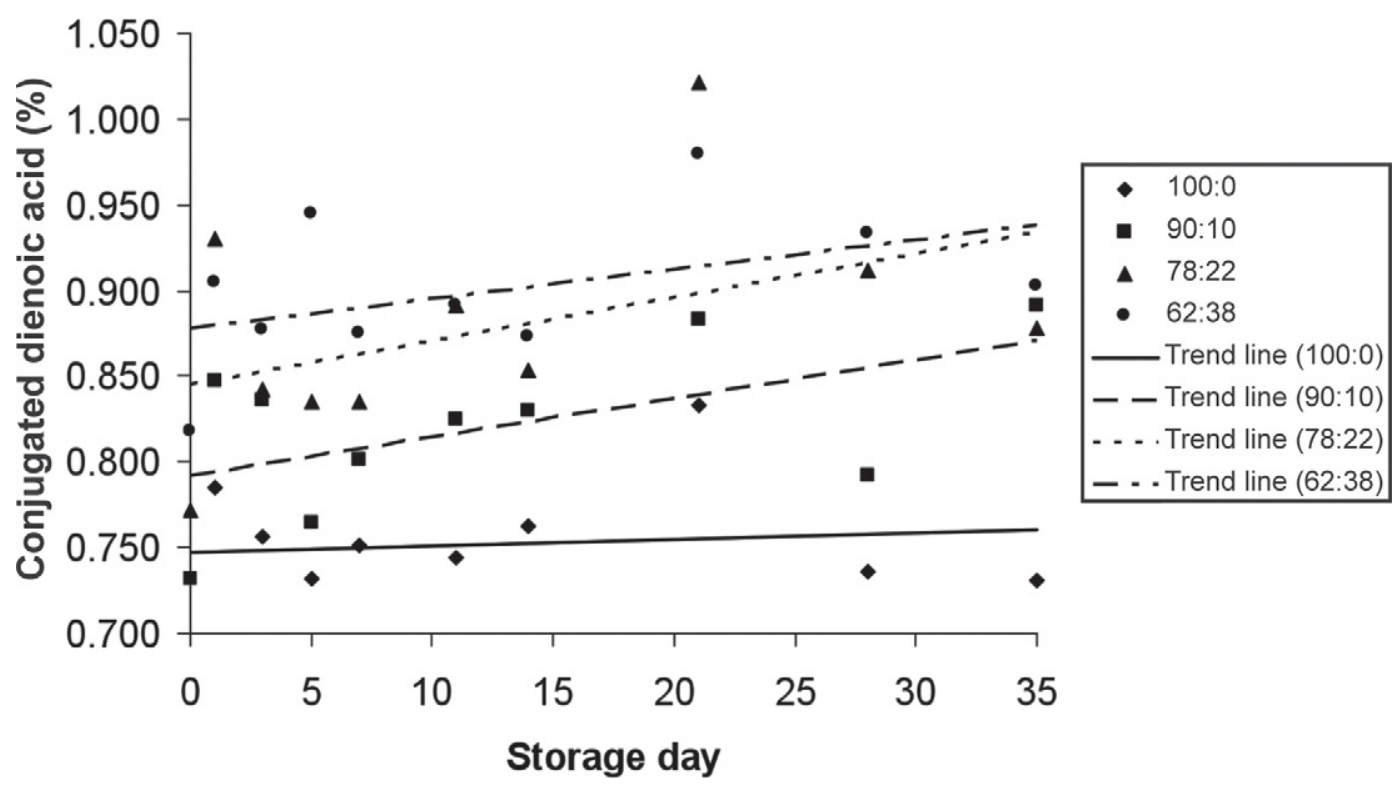

Figure 1. Percentage conjugated dienoic acid for all UHT-processed n-3 FA-fortified dairy-based beverages during $35 \mathrm{~d}$ of storage at $4^{\circ} \mathrm{C}$. Dairy beverages contained different proportions of butter oil to fish oil: 100:0, 90:10, 78:22, and 62:38. 
in oxidized foods. Acetaldehyde, propanal, 2-butanone, 2-pentanone, 1-penten-3-ol, hexanal, and 2-heptanone, which were identified in the n-3 FA-fortified dairy-based beverages, source oils, and commercial shelf-stable UHT milk, were previously reported as present in FO and n-3 FA-enriched dairy products (Hartvigsen et al., 2000; Timm-Heinrich et al., 2004; Venkateshwarlu et al., 2004; Gallaher et al., 2005; Jimenez-Alvarez et al., 2008). Ketones (including 2-butanone, 2-pentanone, and 2-heptanone) are abundant in UHT-pasteurized milk and other compound classes, including aldehydes, terpenes, and sulfur and aromatic compounds are also present (Contarini et al., 1997).

Figure 2 shows a comparison of the major volatile compound peaks between $\mathrm{d} 0$ and 35 of the 78:22 BO:FO formulation. Peak areas for 2-butanone, 1-penten-3-ol, and 2-heptanone increased during storage, suggesting oxidation with storage time, whereas areas for propanal and hexanal decreased. The decrease in propanal and hexanal levels during storage contradicts previous studies (Medina et al., 1999; Iglesias et al., 2007; JimenezAlvarez et al., 2008), which showed increases in hexanal levels as storage time and oxidation increased. The observed decrease in hexanal levels suggests that its formation from primary oxidation products may have been inhibited during storage, possibly due to antioxidants present in the FO (as stated on the FO product label), and it decomposed into shorter-chain volatile compounds that were not measured, such as lower aldehydes, hydrocarbons, alcohols, and acids (Frankel 1983). Frankel (1984) reported that propanal, formed from the decomposition of linolenate hydroperoxides, can further decompose via removal of 2 hydrogen radicals into propenal, which may explain the reduction in propanal observed in this study. Jimenez-Alvarez et al. (2008) studied the volatile compounds produced in milk containing $5 \% \mathrm{FO}(\mathrm{vol} / \mathrm{vol}$ ) and reported that hexanal and 1-penten-3-ol were some of the most abundant volatile compounds formed, and their levels increased during storage at $37^{\circ} \mathrm{C}$. Frankel (2005) reported the formation of 1-penten-3-ol in oxidized cod oil and Jafar et al. (1994) reported that the formation of this compound in FO-enriched mayonnaise was a result of enzymatic reactions. Hexanal is derived from linoleate hydroperoxide decomposition (Frankel, 1980, 1983), which may originate from canola and sunflower oils in the commercial FO. Jimenez-Alvarez et al. (2008) and Hartvigsen et al. (2000) reported the formation and increase in levels of 1-penten-3-ol during storage of FOenriched milk and mayonnaise products.

\section{Effect of FO Levels on Aroma Perception}

The aroma effect of FO addition to dairy products has been extensively studied (Let et al., 2004; Let et al., 2005; Kolanowski and Weißbrodt, 2007; JimenezAlvarez et al., 2008). Venkateshwarlu et al. (2004) concluded that the volatile compounds that contribute to the odor profile of FO-enriched milk are secondary oxidation products: vinyl ketones, alkenals, and alkadienals. In a study on FO-fortified mayonnaise and milk drinks, Timm-Heinrich et al. (2004) reported that the

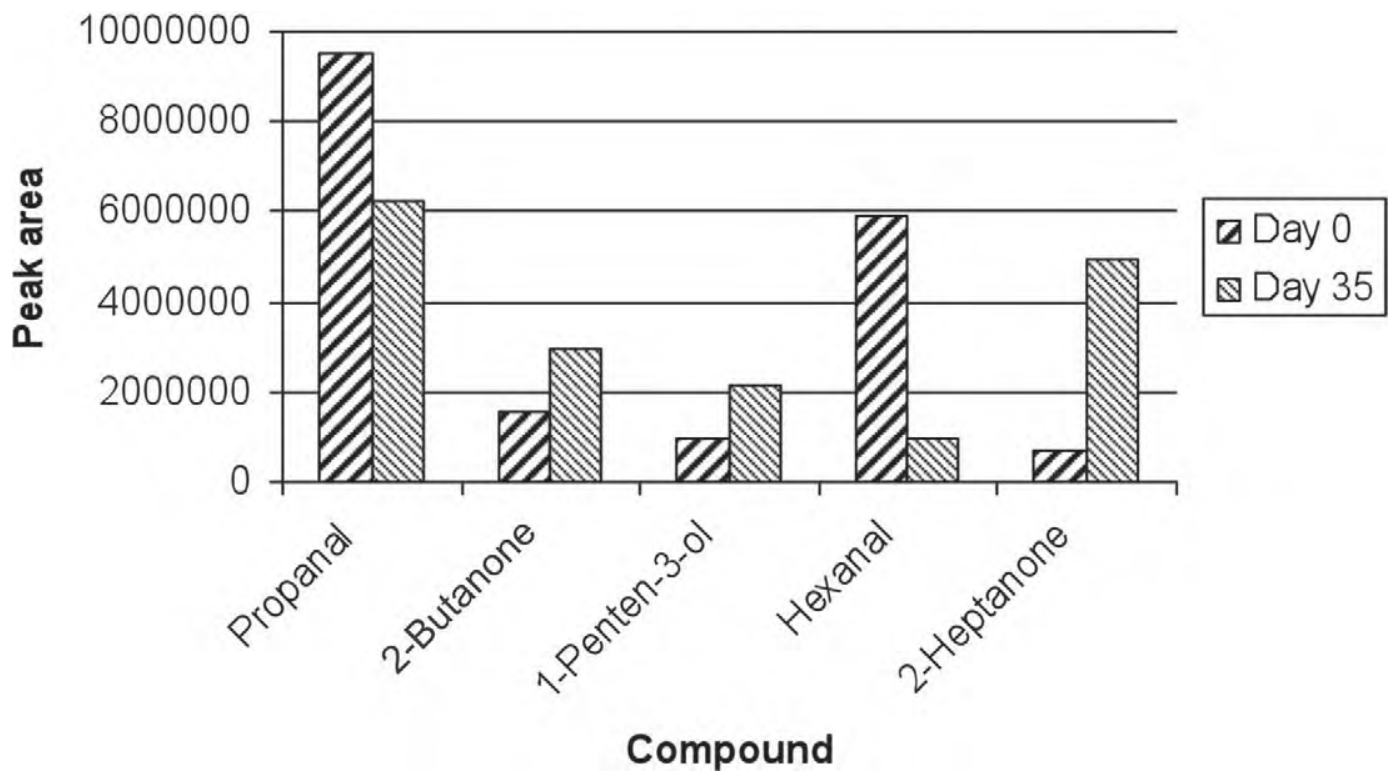

Figure 2. Comparison of major volatile compounds identified in headspace analysis chromatograms of an n-3 FA-fortified dairy-based beverage (78:22 butter oil:fish oil formulation) on d 0 and 35 of storage $\left(4^{\circ} \mathrm{C}\right)$. 
decrease in overall sensory quality of fortified products, via development of fishy off-flavors, was a result of oxidative deterioration. Let et al. (2003) reported that milk could be enriched with FO at high levels (15 $\mathrm{g}$ of $\mathrm{FO} / \mathrm{kg}$ of milk) without significant development of fishy off-flavors during storage at $2^{\circ} \mathrm{C}$, provided the initial level of oxidation of the FO was low before emulsion formulation.

Ultra-high temperature-processed milk has a "cooked" aroma due to the high pasteurization temperatures used. This aroma is different than the aroma of HTST-pasteurized milk. The cooked aroma of a UHTprocessed dairy-based beverage, including the aroma contributions of free sulfhydryl groups resulting from UHT pasteurization (Hutton and Patton, 1952; Taylor and Richardson, 1980), may overpower and mask aromas resulting from FO fortification in the early stages of storage. After 1 wk of storage, the dairy-based beverage (3.1\% fat) was not significantly different $(P>0.05)$ in aroma from the control (commercially processed $2 \%$ UHT shelf-stable milk). Only $16 \%$ of panelists were able to correctly identify the different sample in both tests. The potential for the formulated beverage, with a higher fat and addition of FO, to have a stronger aroma was anticipated but not observed. This suggests that the FO did not have a major contribution to the aroma profile of the product.

\section{CONCLUSIONS}

Incorporating FO into a dairy-based beverage system to deliver a daily level of n-3 FA sufficient for promoting heart health (432 $\mathrm{mg}$ of $\mathrm{n}-3 \mathrm{FA} / 250 \mathrm{~mL}$ ) can be accomplished with limited effect on storage stability and analytical indicators of oxidation. It is possible to add FO to a dairy-based beverage system with little aroma effect.

\section{REFERENCES}

AHA (American Heart Association). 2010. Fish 101. Accessed Dec. 17, 2011. http://www.heart.org/HEARTORG/GettingHealthy/ NutritionCenter/Fish-101_UCM_305986_Article.jsp\#.Tu0OWFamWSo.

AOCS (American Oil Chemists' Society). 1998. Official Methods and Recommended Practices of the American Oil Chemists' Society. 5th ed. AOCS Press, Champaign, IL.

Cant, J. P., A. H. Fredeen, T. MacIntyre, J. Gunn, and N. Crowe. 1997. Effect of fish oil and monensinon milk fat composition in dairy cows. Can. J. Anim. Sci. 77:125-131.

Contarini, G., M. Povolo, R. Leardi, and P. M. Toppino. 1997. Influence of heat treatment on the volatile compounds of milk. J. Agric. Food Chem. 45:3171-3177. http://dx.doi.org/10.1021/ jf960849s.

Donovan, D. C., D. J. Schingoethe, R. J. Baer, J. Ryali, A. R. Hippen, and S. T. Franklin. 2000. Influence of dietary fish oil on conjugated linoleic acid and other fatty acids in milk fat from lactating dairy cows. J. Dairy Sci. 83:2620-2628. http://dx.doi.org/10.3168/jds. S0022-0302(00)75155-1.

Elling, J. L., and S. E. Duncan. 1996. Physical properties of $20 \%$ milk fat reformulated creams manufactured from cholesterol-reduced butteroil. J. Food Sci. 61:375-378.

FDA (Food and Drug Administration). 2004. FDA Announces qualified claims for omega-3 fatty acids. Accessed Dec. 17, 2011. http://www.fda.gov/NewsEvents/Newsroom/PressAnnouncements/2004/ucm108351.htm.

Folch, J., M. Lees, and G. H. Sloane Stanley. 1957. A simple method for the isolation and purification of total lipids from animal tissues. J. Biol. Chem. 226:497-509.

Frankel, E. N. 1980. Lipid oxidation. Prog. Lipid Res. 19:1-22.

Frankel, E. N. 1983. Volatile lipid oxidation products. Prog. Lipid Res. 22:1-33. http://dx.doi.org/10.1016/0163-7827(83)90002-4.

Frankel, E. N. 1984. Lipid oxidation: Mechanisms, products, and biological significance. J. Am. Oil Chem. Soc. 61:1908-1917. http:// dx.doi.org/10.1007/BF02540830.

Frankel, E. N. 1991. Review. Recent advances in lipid oxidation. J. Sci. Food Agric. 54:495-511. http://dx.doi.org/10.1002/ jsfa. 2740540402 .

Frankel, E. N. 1998. Lipid Oxidation. The Oily Press Ltd., Dundee, UK.

Frankel, E. N. 2005. Lipid Oxidation. 2nd ed. The Oily Press Ltd., Dundee, UK.

Gallaher, J. J., R. Hollender, D. G. Peterson, R. F. Roberts, and J. N. Coupland. 2005. Effect of composition and antioxidants on the oxidative stability of fluid milk supplemented with an algae oil emulsion. Int. Dairy J. 15:333-341. http://dx.doi.org/10.1016/j. idairyj.2004.08.010.

Hartvigsen, K., P. Lund, L. F. Hansen, and G. K Hølmer. 2000. Dynamic headspace gas chromatography/mass spectrometry characterization of volatiles produced in fish oil enriched mayonnaise during storage. J. Agric. Food Chem. 48:4858-4867. http://dx.doi. org/10.1021/jf991385b.

Hooi, R., D. M. Barbano, R. L. Bradley, D. Budde, M. Bulthaus, M. Chettiar, J. Lynch, and R. Reddy. 2004a. Fat determination methods. Page 408 in Standard methods for the examination of dairy products. 17th ed. H. M. Wehr and J. F. Frank, ed. American Public Health Association, Washington, DC.

Hooi, R., D. M. Barbano, R. L. Bradley, D. Budde, M. Bulthaus, M. Chettiar, J. Lynch, and R. Reddy. 2004b. Moisture and solids tests. Page 442 in Standard methods for the examination of dairy products. 17th ed. H. M. Wehr and J. F. Frank, ed. American Public Health Association, Washington, DC.

Horrocks, L. A., and Y. K. Yeo. 1999. Health benefits of docosahexaenoic acid (DHA). Pharmacol. Res. 40:211-225. http://dx.doi. org/10.1006/phrs.1999.0495.

Hutton, J. T., and S. Patton. 1952. The origin of sulfhydryl groups in milk proteins and their contributions to "cooked" flavor. J. Dairy Sci. 35:699-705. http://dx.doi.org/10.3168/jds.S00220302(52)91658-5.

Iglesias, J., S. Lois, and I. Medina. 2007. Development of a solid-phase microextraction method for determination of volatile oxidation compounds in fish oil emulsions. J. Chromatogr. A 1163:277-287.

Jafar, S. S., H. O. Hultin, A. P. Bimbo, J. B. Crowther, and S. M. Barlow. 1994. Stabilization by antioxidants of mayonnaise made from fish oil. J. Food Lipids 1:295-311.

Jimenez-Alvarez, D., F. Giuffrida, P.-A. Golay, C. Cotting, F. Destaillats, F. Dionisi, and B. Keely. 2008. Profiles of volatile compounds in milk containing fish oil analyzed by HS-SPME-GC/MS. Eur. J. Lipid Sci. Technol. 110:277-283. http://dx.doi.org/10.1002/ ejlt.200700148.

Kolanowski, W., and J. Weißbrodt. 2007. Sensory quality of dairy products fortified with fish oil. Int. Dairy J. 17:1248-1253. http://dx.doi.org/10.1016/j.idairyj.2007.04.005.

Kris-Etherton, P. M., D. S. Taylor, S. Yu-Poth, P. Huth, K. Moriarty, V. Fishell, R. L. Hargrove, G. Zhao, and T. D. Etherton. 2000 Polyunsaturated fatty acids in the food chain in the United States. Am. J. Clin. Nutr. 71(Suppl.):179S-188S. 
Laird, D. T., S. A. Gambrel-Lenarz, F. M. Scher, T. E. Graham, and R. Reddy. 2004. Microbiological count methods. Page 153 in Standard methods for the examination of dairy products. 17th ed. H. M. Wehr and J. F. Frank, ed. American Public Health Association, Washington, DC.

Let, M. B., C. Jacobsen, E. N. Frankel, and A. S. Meyer. 2003. Oxidative flavour deterioration of fish oil enriched milk. Eur. J. Lipid Sci. Technol. 105:518-528. http://dx.doi.org/10.1002/ejlt.200300821.

Let, M. B., C. Jacobsen, and A. S. Meyer. 2004. Effects of fish oil type, lipid antioxidants and presence of rapeseed oil on oxidative flavour stability of fish oil enriched milk. Eur. J. Lipid Sci. Technol. 106:170-182. http://dx.doi.org/10.1002/ejlt.200300901.

Let, M. B., C. Jacobsen, and A. S. Meyer. 2005. Sensory stability and oxidation of fish oil enriched milk is affected by milk storage temperature and oil quality. Int. Dairy J. 15:173-182. http://dx.doi. org/10.1016/j.idairyj.2004.06.003.

Let, M. B., C. Jacobsen, and A. S. Meyer. 2006. Preventing oxidation in milk enriched with omega-3 fatty acids. Lipid Technol. 18:77-81.

Lock, A. L., and D. E. Bauman. 2004. Modifying milk fat composition of dairy cows to enhance fatty acids beneficial to human health. Lipids 39:1197-1206. http://dx.doi.org/10.1007/s11745-004-13486.

Marmesat, S., A. Morales, J. Velasco, M. Ruiz-Mendez, and M. Dobarganes. 2009. Relationship between changes in peroxide value and conjugated dienes during oxidation of sunflower oils with different degree of unsaturation. Grasas Y Aceites 60:155-160. http:// dx.doi.org/10.3989/gya.096908.

Medina, I., M. T. Satué-Gracia, and E. N. Frankel. 1999. Static headspace gas chromatographic analyses to determine oxidation of fish muscle lipids during thermal processing. J. Am. Oil Chem. Soc. 76:231-236. http://dx.doi.org/10.1007/s11746-999-0223-z.

Meilgaard, M. C., G. V. Civille, and B. T. Carr. 2006. Sensory Evaluation Techniques. 6th ed. CRC Press, Boca Raton, FL.

Meyer, B. J., N. J. Mann, J. L. Lewis, G. C. Milligan, A. J. Sinclair, and R. C. Howe. 2003. Dietary intakes and food sources of omega-6 and omega-3 polyunsaturated fatty acids. Lipids 38:391-398. http://dx.doi.org/10.1007/s11745-003-1074-0.

O'Donnell, C. 2008. Healthful ingredients: Drive new products. Page NS7 in Prepared Foods. Business News Publishing Co II LLC, Troy, MI.

Packaged Facts. 2011. Omega-3 ingredient market to grow $40 \%$ by 2015, packaged facts projects. Accessed Dec. 17, 2011. http:// www.packagedfacts.com/about/release. $a s p ? i d=2000$.

Petit, H. V. 2002. Digestion, milk production, milk composition, and blood composition of dairy cows fed whole flaxseed. J.
Dairy Sci. 86:2637-2646. http://dx.doi.org/10.3168/jds.S00220302(02)74217-3.

Petit, H. V., R. J. Dewhurst, N. D. Scollan, J. G. Proulx, M. Khalid, W. Haresign, H. Twagiramungu, and G. E. Mann. 2002. Milk production and composition, ovarian function and prostaglandin secretion of dairy cows fed omega-3 fats. J. Dairy Sci. 85:889-899. http://dx.doi.org/10.3168/jds.S0022-0302(02)74147-7.

Ruxton, C. H. S., S. C. Reed, M. J. A. Simpson, and K. J. Millington. 2004. The health benefits of omega-3 polyunsaturated fatty acids: a review of the evidence. J. Hum. Nutr. Diet. 17:449-459. http:// dx.doi.org/10.1111/j.1365-277X.2004.00552.x.

Shingfield, K. J., C. K. Reynolds, G. Hervás, J. M. Griinari, A. S. Grandison, and D. E. Beever. 2006. Examination of the persistency of milk fatty acid composition responses to fish oil and sunflower oil in the diet of dairy cows. J. Dairy Sci. 89:714-732. http://dx.doi.org/10.3168/jds.S0022-0302(06)72134-8.

Simopoulos, A. P. 1999. Essential fatty acids in health and chronic disease. Am. J. Clin. Nutr. 70(Suppl.):560S-569S.

Sprinkle, D. 2011. Fish oil still has legs. Accessed Dec. 17, 2011. http://www.naturalproductsinsider.com/articles/2011/09/fish-oilstill-has-legs.aspx.

Taylor, M. J., and T. Richardson. 1980. Antioxidant activity of skim milk: effect of heat and resultant sulfhydryl groups. J. Dairy Sci. 63:1783-1795. http://dx.doi.org/10.3168/jds.S00220302(80)83140-7.

Timm-Heinrich, M., X. Xu, N. S. Nielsen, and C. Jacobsen. 2004. Oxidative stability of mayonnaise and milk drink produced with structured lipids based on fish oil and caprylic acid. Eur. Food Res. Technol. 219:32-41. http://dx.doi.org/10.1007/s00217-0040911-8.

USDA (US Department of Agriculture). 2010a. Dietary Guidelines for Americans, 2010. 7th ed. US Department of Agriculture and US Department of Health and Human Services. US Government Printing Office, Washington, DC.

USDA (US Department of Agriculture). 2010b. USDA National Nutrient Database for Standard Reference, Release 23. US Department of Agriculture, Agricultural Research Service. Accessed Dec. 17, 2011. http://www.nal.usda.gov/fnic/foodcomp/search/.

Venkateshwarlu, G., M. B. Let, A. S. Meyer, and C. Jacobsen. 2004 Chemical and olfactometric characterization of volatile flavor compounds in a fish oil enriched milk emulsion. J. Agric. Food Chem. 52:311-317. http://dx.doi.org/10.1021/jf034833v.

WHO (World Health Organization). 2003. Diet, nutrition and the prevention of chronic diseases. Pages 99-100 in Population Nutrient Intake Goals for Preventing Diet-Related Chronic Diseases. WHO, Geneva, Switzerland. 